\title{
Prevalence and determinants of self-directed referrals amongst patients at hospitals in eThekwini District, KwaZulu-Natal 2015
}

\author{
A Rajman and OH Mahomed* (1) \\ Discipline of Public Health Medicine, University of KwaZulu Natal, Durban, South Africa \\ *Corresponding author, email: mahomedo@ukzn.ac.za; ozayr411@gmail.com
}

Background: Non-compliance with designated referral pathways has ramifications such as increased patient waiting time, overburdening of higher levels of care and increasing healthcare costs on patients and the healthcare system. The purpose of this study was to assess the determinants of self-directed referrals amongst patients attending hospitals in the eThekwini district of KwaZulu-Natal.

Methods: An analytic, cross-sectional study was conducted at the Medical Outpatient Departments across five district hospitals in eThekwini using interviewer-administered questionnaires. Descriptive statistics were used to determine the proportion and the most frequent factors contributing towards patient self-referral. The likelihood of patients to self-refer was tested using chisquare $\left(X^{2}\right)$ and a multivariate regression model.

Results: There were 315 patients interviewed with $35 \%(n=109 / 315)$ having self-referred. The majority $(51 \% ; 55 / 107)$ of selfreferrals were male and were of African race $(74 \% ; n=80 / 107)$. Five institutional factors, namely: availability of medication at the pharmacy (98\%); quality of care at the facility (93\%); waiting time at facility (92\%); services provided (90\%); and attitude of healthcare workers (87\%), were ranked as the main drivers of self-referral. Multivariate logistic regression established a significant positive association between patient self-referral and male gender (OR 1.73; $\mathrm{Cl} 1.04-2.87, p<0.05$ ). Age $<39$ years (OR 0.96; $\mathrm{Cl} 0.94-0.99, p<0.05)$; and patient awareness of a referral letter (OR 0.28; $\mathrm{Cl} 0.09-0.86, p<0.05)$ emerged as protective factor against self-referrals.

Conclusion: Males patients tend to bypass the referral pathway whilst younger patients and patients who were aware of a referral letter were less likely to bypass the referral system. In addition to addressing the systemic challenges of waiting times, quality of care and availability of medication, a patient-oriented approach that comprises education, encouragement and increased patient awareness is an important strategy to improve referral pathway compliance.

Keywords: district hospitals, referral system, self-referral

\section{Background}

The legacy of the apartheid policies has largely influenced the delivery of healthcare services in South Africa. Prior to 1994, the healthcare system was fragmented (consisting of 14 health departments), inequitable (resources and distribution favoured the whites and urban population), predominantly curative (preventive primary care services were provided in separate facilities) and hospi-centric. ${ }^{1}$ The post-democratic government introduced a number of pro-equity reforms to restructure the healthcare system. In 1997, the White Paper for the Transformation of the Health System ${ }^{2}$ provided the framework for the restructuring of healthcare services. Primary health care (PHC), delivered via a district health system, was the cornerstone of this policy.

The major early focus of reform was on structurally integrating the 14 individual health departments into a unitary system. The transformation subsequently focused on the organisational structure, authority and organisation of services at a management level. ${ }^{3}$ The primary healthcare package of services, ${ }^{4}$ together with the essential drug lists and standard treatment guidelines were developed and issued for both primary healthcare and hospital levels. ${ }^{1}$ District hospitals were included as part of the district health system. ${ }^{2}$

The implementation of the above policies and reforms resulted in improved access to services to the previously marginalised, realignment of district boundaries, provincialisation of health services and the appointment of district management teams. The preoccupation with organisational structure and authority as a means to an end with very little focus on systems development and service delivery resulted in the under-performance of PHC services in many parts of the country.

In addition, the lack of leadership, poor management of the HIV and AIDS pandemic accompanied by an emerging epidemic of non-communicable disease, including stroke and heart disease, diabetes and cancers; childhood diarrhoea and malnutrition; as well as high levels of violence and accidents resulted in an increase in adult and childhood mortality. Coupled with this complex and evolving burden of disease, health worker shortages, deep-seated imbalance of resources and inequities in the distribution of personnel, a curative-oriented health service, and deficiencies in managerial capacity and health system leadership at all levels limited the achievements of the objectives of the PHC-driven policy. ${ }^{3}$

Increasing life expectancy; decreasing maternal and child mortality; combating HIV and AIDs; decreasing the burden of tuberculosis (TB); and strengthening health system effectiveness were key strategic priorities of the health sector post-2009. ${ }^{5}$ The re-engineered primary healthcare approach was adopted as the service delivery model to strengthen the healthcare system (Figure 1). ${ }^{6}$

The primary healthcare clinic is the first point of contact with the formal health system and patients will either receive the care 


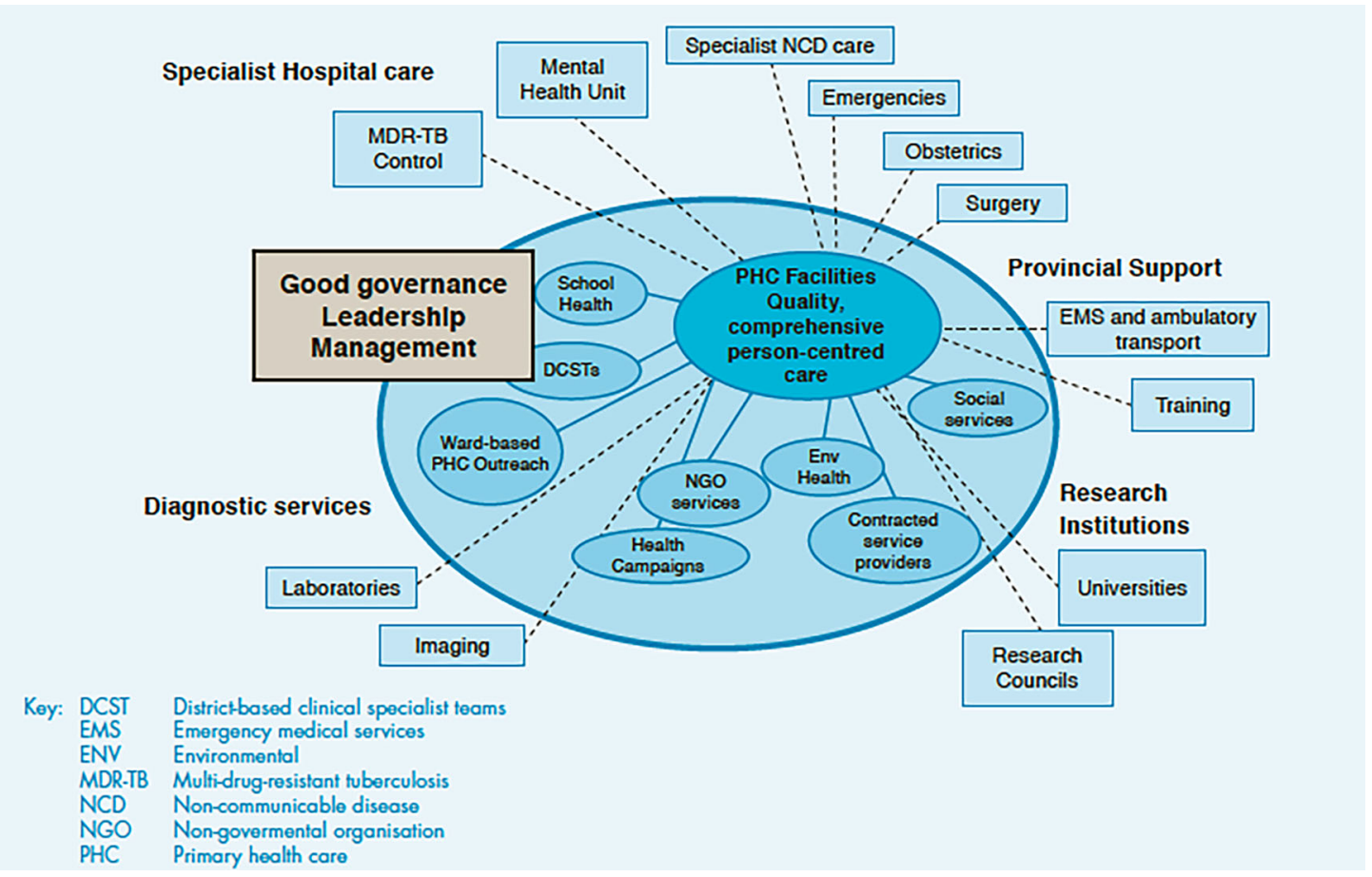

Figure 1. PHC re-engineering framework based on District Health Model. Source: South African Health Review $2014 / 15{ }^{6}$

they need at this level or will be referred to a hospital if more specialised services are necessary. The district hospital has an important dual function: first, the district hospital functions as a referral centre for the healthcare workers (HCWs) providing primary healthcare, e.g. staff employed at community health centres $(\mathrm{CHCs})$ and clinics and private general practitioners, and, second, it acts as a gateway to higher levels of care. ${ }^{7}$

An effective referral system is an integral component of a successful healthcare system as it ensures continuity of patient care. A well-functioning referral system ensures that patients are managed at appropriate levels, preventing overburdening at higher level facilities. ${ }^{8}$

Hospital self-referrals and non-compliance with the designated referral pathway have multiple effects on patients and the healthcare system. These effects vary from increased patient waiting time to overburdening of higher levels of care, decreased primary healthcare utilisation rate and increasing healthcare costs. Bypassing the referral system may result in duplication of investigations and wastage of resources, and delays in effective management and, thus, poorer patient outcomes, diminishing quality of care and an increased level of dissatisfaction between the healthcare user and provider. ${ }^{9-11}$

There is a paucity of studies in South Africa that look specifically at the determinants of self-directed referrals to hospitals amongst patients. The aim of this study was to assess the magnitude and determinants of self-directed referrals amongst patients attending district and combo (district hospitals offering regional hospital services) hospitals in eThekwini district.

\section{Methods}

\section{Study design and setting}

An analytic cross-sectional study was conducted within the eThekwini district, a Metropolitan Health district in KwaZuluNatal, South Africa. The network of healthcare facilities includes eight community health centres, 42 primary health clinics, 22 mobile clinics and 18 hospitals. ${ }^{12}$ Table 1 summarises the profile of study facilities including hospital capacity and budgetary allocation.

\section{Study population}

The study population included all patients older than 18 years who had been referred (correctly or inappropriately) and selfreferred to a district or district/regional hospital medical outpatient department (MOPD) during May and June of 2015.

\section{Study sample}

A sample size of 288 was established using the following parameters: an estimated population self-referral rate of $20 \%$, relative precision of $25 \%$ and $95 \%$ confidence interval. The number

Table 1: Profile of study facilities in eThekwini 2014/2015

\begin{tabular}{lcccc}
\hline Name of hospital & Number of inpatient beds & Outpatient headcount & \multicolumn{1}{c}{ Total number of staff } & Hospital budget for 2014/15 \\
\hline Mahatma Gandhi & 355 & 196675 & 944 & 440 \\
Osindisweni & 301 & 94205 & 1255 & R 157491000 \\
King Dinuzulu & 400 & 184014 & 600 & R 509455000 \\
Wentworth & 214 & 120714 & 1977 & $R 215848000$ \\
Addington & 571 & 370896 & $R 685096000$ & \\
\hline
\end{tabular}

Source: DHIS 
of patients recruited per facility was proportional to the medical outpatient headcounts. Convenience sampling was used to recruit participants. Patients were included until the sample size was met.

\section{Data sources and data collection}

To determine the proportion of self-referrals, a daily data-collection tool was designed for the MOPDs that captured the total number of patients seen for consultation in the MOPD; the total number of patients who presented with a referral letter and the total number of patients who presented without a referral letter was collected for each day during the study period.

A questionnaire was developed by the principal investigator based on existing literature. The questionnaire was pilot tested on 10 independent patients to test for reliability. These patients were not from the participating facilities and were not included in the analysis. Trained research assistants administered questionnaires to patients presenting to the MOPD and those waiting in the queue (for outpatients). Both self-referred and appropriately referred patients who met the inclusion criteria were invited to participate in the study. Self-referrals were identified by the absence of an appointment date or a referral letter, while appropriately referred patients were those who had a referral letter.

\section{Data management and analysis}

Respondent data were verified for completeness and consistency. All questionnaires were uniquely coded, with a participant identity number, date and site of data collection including the name of the data collector. Data were captured and entered into an electronic database, and similar labels to those of hardcopies were used. Entry into the database was access controlled, requiring a password.

The outcome variable was self-referral. The predictor variables were further grouped into individual and institutional variables. Individual variables included: age, gender, marital status, level of education, employment, type of employment, monthly income, number of dependents, family support, type of transport used and area of residence. Institutional variables included: designated local clinic, designated local hospital, regular healthcare provider, access to public transport, proximity of clinic/hospital to home, proximity of clinic/hospital to place of work, waiting time at clinic/hospital, reputation of healthcare facility, attitude of healthcare workers/administrative staff, availability of medicine, operative hours and cleanliness of facility.

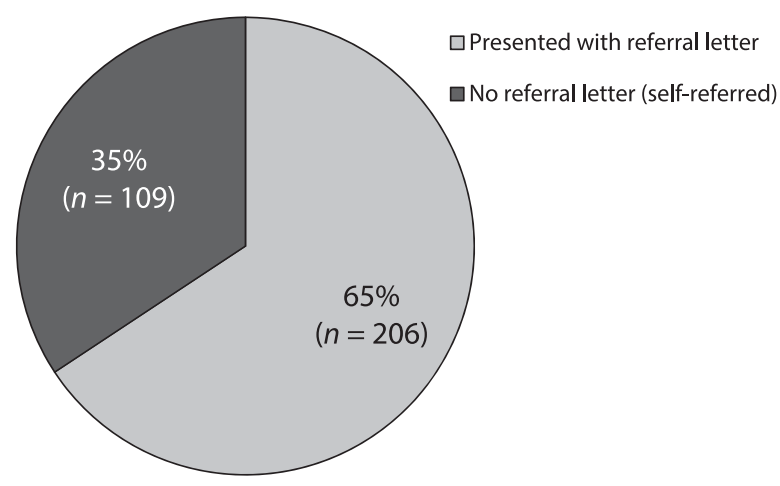

Figure 2: Proportion of appropriately referred and self-referred participants attending eThekwini district and district/regional hospitals in May-June $2015(n=315)$.

\section{Statistical processing}

Descriptive and analytic statistics were computed using the statistical software package Stata (version 13, StataCorp, College Station, TX, USA). Descriptive statistical analysis was conducted to determine proportions and frequencies. Bivariate and multivariateadjusted logistic regressions were also used to assess the influence of different variables or confounders on patient non-compliance. The level of statistical significance for variables in bivariate analysis was determined at $p<0.1$, to negate confounding. Statistically significant variables were then subjected to multivariate analysis with the level of statistical significance at $p<0.05$.

\section{Ethics and permissions}

Ethical approval for this study was granted by the Biomedical Research Ethics Committee of the University of KwaZulu-Natal, Durban (REF: BE462/14). Permission to conduct this study was obtained from the eThekwini Health District Office and the Provincial Health Research and Knowledge Management subcomponent. Written informed consent was obtained from all participants.

Table 2: Frequency table of the sociodemographic profile between referred and self-referred participants at district and district/regional hospitals in eThekwini between May and June $2015(n=315)$

\begin{tabular}{|c|c|c|}
\hline Variable & Appropriate referral & Self-referral \\
\hline \multicolumn{3}{|l|}{ Age } \\
\hline Mean & 34.6 (SD 12.1) & 39.8 (SD 14.5) \\
\hline Median & 32 (IQR 41.5-46.5) & 38 (IQR 28-50) \\
\hline Gender $(n)$ & 207 & 107 \\
\hline Male & $36.7 \%(76)$ & $51.4 \%(55)$ \\
\hline Female & $63.3 \%(131)$ & $48.6 \%(52)$ \\
\hline Race $(n)$ & 207 & 108 \\
\hline African & $65.7 \%(136)$ & $74.1 \%(80)$ \\
\hline Non-African & $34.3 \%(71)$ & $25.9 \%(28)$ \\
\hline White & $1.9 \%(4)$ & $4.6 \%(5)$ \\
\hline Indian & $21.7 \%(45)$ & $7.4 \%(18)$ \\
\hline Coloured & $9.7 \%(20)$ & $4.6 \%(5)$ \\
\hline Other & $1 \%(2)$ & 0 \\
\hline Level of education $(n)$ & 204 & 108 \\
\hline No education & $3.4 \%(7)$ & $4.6 \%(5)$ \\
\hline Below matric. & $40.7 \%(83)$ & $33.3 \%(36)$ \\
\hline Matric. & $37.3 \%(76)$ & $35.2 \%(38)$ \\
\hline Tertiary & $18.1 \%(37)$ & $25.9 \%(28)$ \\
\hline Other education (informal) & $0.5 \%(1)$ & $0.93 \%(1)$ \\
\hline Level of employment ( $n$ ) & 207 & 108 \\
\hline Unemployed & $60.4 \%(125)$ & $60.2 \%(65)$ \\
\hline Employed & $32.9 \%(68)$ & $30.6 \%(33)$ \\
\hline Student & $3.4 \%(7)$ & $6.5 \%(7)$ \\
\hline Retired & $0.5 \%(1)$ & 0 \\
\hline Mode of transport $(n)$ & 207 & 108 \\
\hline Car & $18.8 \%(39)$ & $22.2 \%(24)$ \\
\hline Taxi & $66.2 \%(137)$ & $57.4 \%(62)$ \\
\hline Walking & $11.1 \%(23)$ & $11.1 \%(12)$ \\
\hline Bus & $5.3 \%(11)$ & $10.2 \%(11)$ \\
\hline Other & $1 \%(2)$ & 0 \\
\hline Usual service provider (n) & 200 & 108 \\
\hline Local clinic & $59.5 \%(119)$ & $52.8 \%(57)$ \\
\hline GP & $19 \%(38)$ & $18.5 \%(20)$ \\
\hline Local hospital & $22.5 \%(45)$ & $27.8 \%(30)$ \\
\hline
\end{tabular}




\section{Results}

\section{Study population}

A total of 315 patients attending the MOPD across two district and three combination district/regional hospitals in eThekwini were recruited to participate in the study during the sevenday study period (May 25-28, 2015 and June 8-10, 2015).

\section{Prevalence of patient self-referral}

The overall prevalence of patient self-referral among five hospitals surveyed (district and combination district/regional hospital) in eThekwini was 35\% (107) (Figure 2), with the majority (65\%; 208) being appropriately referred. Addington had the largest number of self-referrals (26.6\%), followed by Osindisweni (22.9\%) and King Dinuzulu hospital (19.3\%). The prevalence of self-referrals to district hospitals was $13.3 \%$, while the prevalence of self-referral to district/regional hospitals was $21.3 \%$.

\section{Profile of self-referred patients}

The mean age of the self-referred participants was 39.8 years (SD: 14.5$)$. In total, $74 \%$ of the self-referrals were African (80) and $26 \%$ (28) were from other race groups $(7.4 \%$ (18) were Indian, $5 \%$ coloured and $5 \%$ white). The majority of the selfreferred patients $(61 \% ; 66)$ had completed secondary school or had a tertiary education, however $60 \%$ (65) of the self-referred patients were unemployed. The majority of self-referred patients used public transport such as a taxi $(57 \% ; 62)$ or a private motor vehicle $(22 \% ; 24)$ to access the health facility. Some $28 \%(30)$ of the self-referrals indicated that the hospital was their facility of choice, whilst $57 \%$ (71) of the self-referred patients usually attended the local clinic and 19\% (20) attended the local general practitioner as first-choice provider (Table 2).

\section{Associations between patient demographics and self- referrals}

The prevalence of self-referral is higher in males than females $(18 \%$ vs. $17 \% ; p<0.1)$; in participants $<39$ years of age versus $>39$ years $(23 \%$ vs. $11 \% ; p<0.02)$ and among African participants in comparison with non-African participants (25\% vs. $9 \% ; p=0.1$ ). (Data not presented in the tables) Bivariate analysis found gender (OR 1.82; $\mathrm{Cl} 1.11-3.00, p<0.1) ;<39$ years of age (OR 1.8; $\mathrm{Cl} 1.08-3.03, p<0.1$ ); race (OR 1.5; Cl 0.9-2.31, $p<0.1$ ); awareness of referral policy (OR $0.53 ; \mathrm{Cl} 0.31-0.92, p<0.1$ ); and awareness of referral letter (OR $0.26 ; \mathrm{Cl} 0.77-0.78, p<0.1)$ to be statistically significant (Table 3 ).

After multivariate analysis male gender (OR 1.73; Cl 1.04-2.87, $p<0.05)$ remained significantly associated with patient selfreferral $(p<0.05)$ Patients who were $<39$ years (OR 0.96; $\mathrm{Cl} 0.94-0.99, p<0.05)$, and those who had knowledge of the requirement for a referral letter (OR 0.28; CI 0.09-0.86, $p<0.05$ ) were less likely to bypass the referral system $(p<0.05$, Table 3). No significant difference in self-referrals was found among factors such as race, marital status, level of income and number of dependants (see Table 3).

\section{Institutional factors and self-referral}

Institutional factors are important factors in ensuring patients attend the appropriate facilities. Medication stock out (98\%; $106 / 108)$; quality of care (93\%; 100/108); facility waiting time (92\%; 97/105); services provided (90\%; 95/106); attitude of healthcare workers and access to transport $(87 \%$; 94/108) were the highest ranked institutional factors for patients bypassing local clinics among self-referrals. Bivariate analysis indicated that that access to public transport ( $\mathrm{OR} 4.3 ; \mathrm{Cl} 0.5-51.6, p=0.1$ ), proximity of facility to home (OR $8 ; \mathrm{Cl} 0.8-406, p<0.1)$, proximity of facility to work (OR $9 ; \mathrm{Cl} 0.8--459, p<0.1$ ), services provided (OR $1.9 \mathrm{Cl} 1.5-7.5, p>0,1)$, facility reputation (OR 1.4; $\mathrm{Cl} 0.4-4.7, p>$ 0,1 ) and facility cleanliness (OR $1.6 \mathrm{Cl} 0.2-10.7 p>0,1$ ) were important considerations for appropriate referral and conversely for self-referrals. In addition, factors such as waiting time, quality of care, attitude of healthcare workers and operating time were more likely to influence self-referrals. However, only proximity of facility to a patient's home and place of work were found to be statistically significant $(p<0.1)$ on bivariate analysis (Table 4$)$. However, after multivariate adjustment none of the factors were statistically significant.

\section{Discussion}

Patient self-referral has multiple implications for the healthcare system in its entirety and principally for service delivery. The overall self-referral (district and district/regional) to a higher level of care was $35 \%$, with the prevalence of self-referrals to district hospitals $13.3 \%$, while the prevalence of self-referral to district/regional hospitals was $21.3 \%$. These findings are lower than other studies in South Africa.

In particular, the self-referral rate is $11 \%$ lower than the previously determined $46 \%$ in an assessment of district hospital outpatients in KwaZulu-Natal. ${ }^{13}$ The differences in self-referral rate could be attributed to the earlier study employing a larger sample for assessing the province. Another local study (Umuziwabantu sub-district) conducted in 2010 that specifically considered the factors related to patients bypassing PHC facilities revealed that $58.3 \%(420 / 720)$ bypassed their local clinic to attend their district hospital. ${ }^{14}$ Interestingly, the prevalence of self-referral as determined by this study for district hospitals only $(13.3 \%)$ is lower than the $19.4 \%$ measured by district hospitals as reported under the eThekwini OPD headcount new indicator in the 2015/16 Annual Performance report. ${ }^{15}$ In addition, the self-referral rate in our study is lower than that of a 2009 study conducted in the Free State, which showed the proportion of self-referrals as $52 \%$. The prevalence of self-referral in the Free State study was determined by patient record review over a period of five working days. ${ }^{16}$

Furthermore, the findings in this current study are strikingly lower than that of patients bypassing PHC level for secondary levels of care in the Western Cape. Data from a study conducted in an emergency department in the Western Cape established a self-referral rate of $88.9 \%(n=209 / 235){ }^{17}$ Emergency departments tend to have a higher self-referral rate in comparison with medical outpatients, ${ }^{18}$ thus explaining the contrast in self-referral proportions.

The lower proportion of self-referral in this study, in contrast to other research, could be attributed to a smaller sample size; the focus of the study was on medical outpatients only. Although on bivariate analysis our findings indicate that $<39$ years of age (OR $1.8 ; \mathrm{Cl} 1.08-3.03, p<0.1)$ showed increased odds of referral, after multivariate analysis patients aged $<39$ years (OR $0.96 ; \mathrm{Cl} 0.94$ $0.99, p<0.05$ ) were less likely to self-refer. This is indicative of confounding and interaction between other sociodemographic factors and age. However, other studies have shown that the younger age factor is associated with self-referral. A descriptive cross-sectional study conducted in Pretoria found that most of their self-referrals $(79 \% ; 278 / 334)$ were less than 45 years of age, ${ }^{19}$ whilst the results from a recent study conducted in Limpopo supported the inference that younger individuals bypass lower levels of care more frequently; 59\% (173/293) of 
Table 3: Bivariate and multivariate analyses assessing participant factors $(n=315)$ and self-referral in eThekwini district and district/regional hospitals between May and June 2015

\begin{tabular}{|c|c|c|c|c|c|c|c|}
\hline \multirow[b]{2}{*}{ Variable } & \multicolumn{4}{|c|}{ Bivariate analysis } & \multicolumn{3}{|c|}{ Multivariate analysis } \\
\hline & Unadjusted OR & $\mathrm{Cl}$ & $x^{2}$ test of significance & $p$-value & Adjusted OR & $\mathrm{Cl}$ & $p$-value \\
\hline \multicolumn{8}{|l|}{ Gender: } \\
\hline \multicolumn{8}{|l|}{ Age: } \\
\hline$<39$ years & 1.8 & $1.08-3.03$ & 5.7 & 0.02 & 0.96 & $0.94-0.99$ & $0.005^{*}$ \\
\hline \multicolumn{8}{|l|}{ Race: } \\
\hline African & 1.5 & $0.9-2.6$ & $2.31(1)$ & 0.1 & 1.3 & $0.72-2.43$ & \\
\hline Income: & & $0.7-4.9$ & $1.67(1)$ & 0.2 & 0.50 & $0.2-1.27$ & 0.147 \\
\hline \multicolumn{8}{|l|}{ Marital status: } \\
\hline Never married & 1.5 & $0.9-2.5$ & $3.07(1)$ & 0.08 & 1.04 & $0.55-1.96$ & 0.905 \\
\hline \multicolumn{8}{|l|}{ Dependants } \\
\hline Yes & 0.7 & $0.4-1.3$ & $1.4(1)$ & 0.2 & 1.97 & $1.00-3.87$ & 0.049 \\
\hline Yes & 0.53 & $0.31-0.92$ & 5.91 & 0.02 & 0.70 & $0.39-1.27$ & 0.245 \\
\hline \multicolumn{8}{|c|}{ Awareness of referral letter: } \\
\hline Yes & 0.26 & $0.77-0.78$ & 7.51 & 0.0061 & 0.28 & $0.09-0.86$ & $0.026^{*}$ \\
\hline
\end{tabular}

*Level of statistical significance $p<0.1$.

patients between the ages of 20-39 had bypassed their local clinic. $^{20}$ Self-referral in the category of younger age may be attributed to young people having to travel more frequently, possibly as a consequence of employment, and thus seeking care directly from a hospital as it may be closer in proximity.

Male gender (OR 1.73; Cl 1.04-2.87) was significantly associated with patient self-referral. This current finding is similar to those reported from a Dutch study, which found that more than half of their study population were males (54\%; vs. $48 \%){ }^{21}$ Other South African studies have not analysed gender as a predictor of self-referral, but all local studies consistently report a higher proportion of females who self-refer in their respective study population. However, possible reasons attributable to male self-referral may include their employment commitments and perceptions of better quality of care available at higher levels. Some studies have alluded to the difference in perception of health risk between males and females as an explanation for bypass behaviour. ${ }^{22}$

Multivariate analysis suggested that patients who were aware of the requirement for a referral letter and referral policy for hospital attendance were less likely to self-refer. Although this finding supports other studies that have shown patients' failure to understand the prescribed pathway and its significance as being amongst the reasons for patients bypassing the prescribed referral system, ${ }^{23}$ awareness alone may not be sufficient to prevent self-referrals, as a 2010 cross-sectional study in KwaZulu-Natal established that the majority of respondents who bypassed the primary health clinic (76\%) were aware of the existence of a referral system between their local clinic and hospital. ${ }^{24}$

The patient's experience during the first contact with a healthcare provider does influence a patient's perception of quality of care rendered and will determine whether a patient will subsequently comply or switch to another provider. ${ }^{25}$ The current study showed that about a third (33\%) of patients perceive healthcare received at a hospital to be better in contrast to $21 \%$ of patients who felt that their local clinic was better. Similar results were reported among self-referrals to a provincial hospital in the Western Cape where $23.7 \%(n=277)$ of patients had self-referred as they felt that treatment at a hospital was better. ${ }^{17}$ Patients may be willing to spend more of their own resources (time and money) to attend a healthcare facility that they perceive has better care. Such inferences have key ramifications for interventions, which warrant either scaling up lower levels of care or improving patient perceptions of care rendered at proximal facilities.

Availability of medication at the pharmacy was cited as a key factor influencing choice of facility in both the referred and self-referred groups ( $96 \%$ vs. $98 \%$ ). Contrary to these findings, a study conducted in Limpopo showed that only 5.1\% (15/ 293) of patients had self-referred because medicines were unavailable at their local clinic ${ }^{20}$ even though $41 \%(121 / 293)$ of patients reported that their local clinic was not consistently well stocked with pharmaceuticals and thus these were often unavailable to patients. Findings from both studies indicate that patient self-referral may be driven by historical memory or by perception of lack of medication at local clinics. This false perception increases the inclination to self-refer, resulting in underutilised primary healthcare services.

Increased waiting time is frequently cited as a determinant of bypass behaviour. In this study, time spent waiting at the healthcare facility was found to be similarly important between referrals and self-referrals (93\% vs. $92 \%$ ). A previous study conducted in Pretoria, South Africa indicated that $24 \%(n=84 / 334)$ of selfreferrals cited long queues and 25\% $(n=88 / 334)$ increased waiting time at their local facility to explain bypass behaviour. ${ }^{19}$ Although waiting time has been ascertained as a key institutional factor; self-referral behaviour further increases the waiting time at higher levels of care.

The importance of access to transport among self-referral sub groups (compared with other institutional factors) in this study appears to be far less. Accessibility of transport (89\% vs. $87 \%$ ) was also similarly rated in referred and self-referred patients as influencing their selection of health facility. It should be noted that the current study was conducted at facilities where access to transport is not a challenge. A previous study conducted in 2010 in Umuziwabantu sub-district in KZN showed that a 
Table 4: Analysis of institutional factors between referrals and self-referrals in eThekwini district and district/regional hospitals between May and June 2015

\begin{tabular}{|c|c|c|c|c|}
\hline Variable & Unadjusted OR & $\mathrm{Cl}$ & $X^{2}$ test of significance/Fisher's exact test & $p$-value \\
\hline \multicolumn{5}{|c|}{ Public transport: } \\
\hline Clinic & 4.3 & $0.5-51.6$ & 2.8 & 0.1 \\
\hline \multicolumn{5}{|c|}{ Proximity of facility to home: } \\
\hline Clinic & 8 & $0.7-406$ & 4.2 & $0.04^{*}$ \\
\hline \multicolumn{5}{|l|}{ Hospital } \\
\hline \multicolumn{5}{|c|}{ Proximity of facility to work: } \\
\hline Clinic & 9.0 & $0.8-459.2$ & 4.9 & $0.03^{*}$ \\
\hline \multicolumn{5}{|l|}{ Hospital } \\
\hline \multicolumn{5}{|c|}{ Services provided: } \\
\hline \multicolumn{5}{|l|}{ Clinic } \\
\hline Hospital & 1.9 & $0.5-7.5$ & 1.00 & 0.3 \\
\hline \multicolumn{5}{|l|}{ Clinic } \\
\hline \multicolumn{5}{|l|}{ Hospital } \\
\hline \multicolumn{5}{|c|}{ Facility reputation: } \\
\hline \multicolumn{5}{|l|}{ Clinic } \\
\hline Hospital & 1.4 & $0.4-4.7$ & 0.4 & 0.5 \\
\hline \multicolumn{5}{|c|}{ Attitude of HCW: } \\
\hline Clinic & 0.4 & $0.1-2.1$ & 1.5 & 0.2 \\
\hline \multicolumn{5}{|l|}{ Hospital } \\
\hline \multicolumn{5}{|c|}{ Availability of medicines: } \\
\hline \multicolumn{5}{|l|}{ Clinic } \\
\hline Hospital & 1.0 & $0.3-3.9$ & 0.00 & 1 \\
\hline \multicolumn{5}{|l|}{ Quality of care: } \\
\hline \multicolumn{5}{|l|}{ Clinic } \\
\hline \multicolumn{5}{|c|}{ Facility cleanliness: } \\
\hline \multicolumn{5}{|l|}{ Clinic } \\
\hline Hospital & 1.6 & $0.2-10.7$ & 0.3 & 0.6 \\
\hline \multicolumn{5}{|c|}{ Facility operating hours: } \\
\hline \multicolumn{5}{|l|}{ Clinic } \\
\hline Hospital & 0.8 & $0.2-3.5$ & 0.2 & 0.7 \\
\hline
\end{tabular}

*Level of statistical significance $p<0.1$. HCW $=$ healthcare worker.

small proportion (13\%; $n=57 / 436)$ of patients bypassed their proximal clinic as a result of the unavailability of transport. ${ }^{24}$

\section{Study limitations}

Although due diligence was taken to ensure that the study remained scientifically sound and limitations were minimised at every stage, the following limitations were encountered which may have impacted the findings of the study. The sample was conveniently selected. During the week of data collection in May 2015, there was a public-sector taxi strike, resulting in reduced patient numbers at MOPDs. Therefore, a true snapshot of patient characteristics in relation to self-referral may not have been possible. The majority of patients who utilised the taxi service and were likely to bypass the referral system did not attend the hospital, thus limiting the range of participants. However, a second week of data collection was added in June 2015 to adjust for this anomaly and reduce the selection bias. Although patients were assured that confidentiality would be maintained and their participation in the study would not influence their medical consultation, many were still reluctant to participate.
Respondent bias in the study was beyond the control of the investigator. Participants across all facilities may not have been honest in their responses to the questionnaires as they may have felt that it would negatively impact their healthcare service (similar to participation bias). There may have been an element of social desirability bias among some participants.

The inherent nature of this study design provided only a snapshot of the determinants of self-directed referrals among a sample of patients in eThekwini district. Although more than one factor (individual and/or institutional) may contribute towards the decision to self-refer, causality cannot be ascertained.

\section{Conclusion}

South Africa has focused on improving institutional factors with the assumption that this would reduce self-referral behaviour among patients. However, the findings from this study suggest that in addition to institutional factors there are individual factors which also influence self-referral. This interplay of institutional and individual factors requires a more patientorientated approach to addressing the inefficiencies of patients 
bypassing the primary point of care. Education, encouragement and increased patient awareness are strategies to improve referral pathway compliance. In addition, more extensive research is required across all levels of facilities to build the case for appropriate interventions to reduce self-referrals.

Disclosure statement - No potential conflict of interest was reported by the authors.

\section{ORCID}

OH Mahomed (D) http://orcid.org/0000-0001-8076-0453

\section{References}

1. Coovadia $H$, Jewkes $R$, Barron $P$, et al. The health and health system of South Africa: historical roots of current public health challenges. Lancet. 2009;374:817-834. doi:10.1016/S0140-6736(09)60951-X.

2. National Department of Health. White paper on the transformation of the health system. Pretoria: Government Gazette; 1997.

3. Kautzy K, Tollman S. A perspective on primary healthcare in South Africa. In: Barron P, Rona-Readon J, editors. South African health review 2008. Durban: Health System Trust; 2008:17-30.

4. National Department of Health. The primary health care package for South Africa - a set of norms and standards. Pretoria: National Department of Health; 2000.

5. Presidency of South Africa. Negotiated national service delivery agreement 2010-2014. Pretoria: Department of Performance Monitoring and Evaluation; 2010.

6. National Department of Health. Re-engineering primary health care in South Africa: discussion document. Pretoria: National Department of Health; 20.

7. National Department of Health. Regulation 185 of national health act 61 of 2003. Pretoria: Government Gazette, 2012.

8. Hensher M, Price M, Adomakoh S. Referral hospitals. In: Jamison DT, Breman JG, Measham AR, et al., editors. Disease control priorities in developing countries. 2nd ed. Washington DC: The World Bank and Oxford University Press; 2006, p. 1211-1229.

9. Anderson R, Barbara A and Feldman S. What patients want: a content analysis of key qualities that influence patient satisfaction. J Med Pract Manage. 2007;22:255-261.

10. Parchman ML, Noel PH, Lee S. Primary care attributes, health care system hassles, and chronic illness. Med Care. 2005;43:1123-1129.

11. Audet AM, Davis K, Schoenbaum SC. Adoption of patient-centered care practices by physicians: results from a national survey. Arch Intern Med. 2006;166:754-759. doi:10.1001/archinte.166.7.754.
12. eThekwini District Office. Ethekwini district annual performance plan. Durban: KwaZulu Department of Health; 2015.

13. Government of South Africa. Strategic position statement for KwaZulu-Natal. Pretoria: National Department of Health; 2001.

14. Ntleko TL. Determining the factors related to patients in the Umuziwabantu sub-district of KwaZulu-Natal bypassing primary health care facilities in 2010 and accessing the district hospital as their point of first contact. Durban: University of KwaZulu Natal; 2010.

15. KwaZulu Natal Department of Health. 2015/16 Annual report. Pietermaritzburg: KwaZulu Natal Department of Health; 2016.

16. Mojaki $M$, Basu D, Letskikgohka $M$, et al. Referral steps in district health system are side-stepped. S Afr Med J. 2011;101:109.

17. Becker J, Dell A, Jenkins L, et al. Reasons why patients with primary health care problems access a secondary hospital emergency centre. S Afr Med J. 2012;102:800-801. doi:10.7196/samj.6059.

18. Hanewinckel $R$, Jongman HP, Wallis $L A$, et al. Emergency medicine in Paarl, South Africa: a cross-sectional descriptive study. Int J Emerg Med. 2010;3:143-150. doi:10.1007/s12245-010-0185-9.

19. AT M-M, I G and JV N. Reasons patients leave their nearest healthcare service to attend Karen Park clinic, Pretoria North. Afr J Prim Health Care Family Med. 2013;5:559. doi:10.4102/phcfm.v5i1.559.

20. Visser CA, Marincowitz GJO, Govender I, et al. Reasons for and perceptions of patients with minor ailments bypassing local primary health care facilities. S Afr Fam Pract. 2015;57:333-336. doi:10.1080/ 20786190.2015.1102538.

21. van der Linden MC, Lindeboom $R$, van der Linden $N$, et al. Self-referring patients at the emergency department: appropriateness of ED use and motives for self-referral. Int J Emerg Med. 2014;7:28. doi:10.1186/s12245-014-0028-1.

22. Ilboudo TP, Chou YJ, Huang N. Compliance with referral for curative care in rural Burkina Faso. Health Policy Plan. 2012;27:256-264. doi:10.1093/heapol/czr041.

23. Abodunrin OL, Akande TM, Osagbemi GK. Awareness and perception toward referral in health care: a study of adult residents in llorin, Nigeria. Ann Afr Med. 2010;9:176-180. doi:10.4103/1596-3519.68359.

24. Ntleko T. Determining the factors related to patients in the Umuziwabantu sub-district of KwaZulu-Natal bypassing primary health care facilities in 2010 and accessing the district hospital as their point of first contact. Durban: University of KwaZulu Natal; 2010.

25. Mugisha F, Bocar K, Dong H, et al. The two faces of enhancing utilization of health-care services: determinants of patient initiation and retention in rural Burkina Faso. Bull World Health Organ. 2004;82:572-579. doi:/S0042-96862004000800006.

Received: 15-11-2018 Accepted: 11-02-2019 